\title{
Presunção de periculosidade no pensamento jurídico-penal brasileiro de meados do século $\mathrm{XX}^{1}$
}

\author{
Patrícia Graziela Gonçalves ${ }^{2}$
}

\begin{abstract}
Resumo
Em meio às transformações ocorridas na sociedade brasileira entre os anos de 1945 e 1964, constituiu-se no pensamento jurídico-penal a idéia de que determinados segmentos sociais estavam mais propensos ao crime por seu não-ajustamento à sociedade pretensamente moderna do período. Esta "presunção de periculosidade" é o objeto de estudo deste artigo, que se baseia na análise de obras importantes na área da história social do direito, bem como em alguns artigos escritos por juristas em revistas especializadas no campo do direito.
\end{abstract}

Palavras-Chave: Pensamento jurídico; Dinâmica social; Periculosidade.

\section{Introdução}

Entre os anos de 1945 e 1964, o Brasil passou por intensas transformações econômicas e sociais, acarretando um grande processo de urbanização, modernização e industrialização da sociedade e possibilitando mudanças nos padrões sócio-culturais e, consequentemente, no pensamento jurídico-penal. Nesse sentido, esse artigo pretende fazer uma reflexão sobre a constituição, no pensamento jurídico-penal brasileiro, de determinada concepção sobre alguns segmentos sociais, que foram presumidamente considerados perigosos, por sua realidade sócioeconômica, em face da sociedade pretensamente moderna do período, sendo, assim, mais propensos ao crime.

Para o desenvolvimento das nossas reflexões, partimos do pressuposto de que as práticas jurídico-penais não podem ser analisadas sem se levar em consideração a realidade histórica onde ocorre o processo de movimentação das normas jurídicas. Assim, as teorias penais possuem historicidade, não podendo ser estudas somente a partir da lógica jurídica. Para George Rusche e Otto Kirchheimer (2004, p. 19), pensadores da Escola de Frankfurt, "a afinidade, mais ou menos

\footnotetext{
${ }^{1}$ Este trabalho apresenta algumas discussões de uma pesquisa mais ampla, ora em andamento, sobre 0 imaginário jurídico sobre o comportamento de determinados segmentos da sociedade brasileira entre os anos de 1945 e 1964.

${ }^{2}$ Mestranda em História - Universidade Estadual de Maringá.
}

Revista de Direito Púbuco, LondRINA, V, 4, N. 3, P. 254-267, SET./ DeZ. 2009. 
transparente, que se supõe existir entre delito e pena impede qualquer indagação sobre o significado independente da história dos sistemas penais".

Segundo Manuel Hespanha (1978, p. 24), é necessário conhecer os mecanismos "através dos quais é garantida a adequação entre o ordenamento jurídico e o equilíbrio político de uma dada formação social". Isto porque, de acordo com Rivail Carvalho Rolim (2005), as relações sociais em uma realidade historicamente determinada possuem "relação direta com as formulações elaboradas pelos operadores jurídicos, que são materializadas tanto nos ordenamentos jurídicos como nos procedimentos do legalismo processual".

Assim sendo, de acordo com Rolim (2006), para a análise do pensamento jurídico-penal, é necessária uma abordagem histórica, sob pena de não se entender a relação existente entre os sistemas de punição e as realidades históricas determinadas. Como diz Von Savigny (2004, p. 30), expoente da Escola Histórica de Direito na Alemanha, o direito positivo tem por essência não ser mais estático e oferecer uma sucessão contínua de desenvolvimentos, logo, carecemos de conferirIhe a característica da mutabilidade no tempo. Antonio Manuel de Hespanha (1978) ressalta um aspecto importante, o de que a prática jurídica corresponde a uma efetiva reclamação por parte da realidade social, econômica e política.

Nessa mesma direção, Pierre Bourdieu (1989) escreve que o direito não deve ser entendido como um sistema de valores e conceitos fechado e autônomo, cujo desenvolvimento só poder ser compreendido e entendido segundo a sua "dinâmica interna". No entanto, não podemos perder de vista que a prática e os discursos jurídicos são compostos pelas relações de força específicas, que estão na sua própria estrutura e que orientam os conflitos de competência.

Posto isso, é necessário frisar que a análise do pensamento jurídico é de suma importância para a compreensão do processo de elaboração do ordenamento jurídico a partir dos padrões sócioculturais presentes na sociedade. Segundo Gizlene Neder (1995, p. 13):

0 pensamento jurídico é de especial relevância, quer pela inserção dos juristas enquanto intelectuais e produtores de conhecimentos, quer pelas suas múltiplas interferências em vários campos do saber: geografia, economia, história do Brasil, escritas por juristas e, sobretudo, sua interferência nas questões atinentes a instituição policial.

Em função do exposto, na primeira parte do trabalho, apresentaremos a conjuntura histórica delimitada para pesquisa, tentando apreender as condições sociais que permitiram a constituição da presunção de periculosidade sobre determinados segmentos da sociedade. Na segunda parte do trabalho, analisaremos as idéias jurídico-penais, identificando como se 
articulou o novo conceito de periculosidade referente aos segmentos sociais que constituíam as multidões das grandes cidades.

\section{Do contexto histórico}

A sociedade brasileira do pós Segunda Guerra Mundial e fim do Estado Novo se insere num processo de modernização e industrialização sem precedentes. As transformações são de tamanha intensidade que dão nova configuração as cidades como São Paulo, por exemplo. Segundo Maria Armandina do Nascimento Arruda (2001, p. 18), essas mudanças estavam associadas à idéia de progresso, no plano mais imediato, e manifestava-se nos diferentes modos de reconhecimento do moderno. Sobre este período, escreve João Manuel C. Mello e Fernando Novais (1998, p. 561-562)

Entre 1945 e 1964, vivemos os momentos decisivos do processo de industrialização, com a instalação de setores tecnologicamente mais avançados, que exigiam investimentos de grande porte; as migrações internas e a urbanização ganham um ritmo acelerado.

A elite brasileira do período estava otimista com esse aparente progresso e manifestava a crença de que o Brasil poderia em pouco tempo ingressar no "Primeiro Mundo". Isso porque as conquistas materiais davam a impressão de um grande salto econômico, que possibilitaria 0 acesso das classes mais abastadas a produtos eletroeletrônicos como a televisão e a geladeira, fogão, dentre outros; a alimentos industrializados; a vestuários mais modernos e a hábitos antes inexistentes, como "comer fora", por exemplo (MELLO; NOVAIS, 1998).

No entanto, esse processo de desenvolvimento do país implicou em transferências maciças de população das zonas rurais para as urbanas, formando grandes correntes migratórias. Eunice Ribeiro Durhan (1978, p. 20) escreve sobre essa conjuntura:

No Brasil, o desenvolvimento econômico resultante da industrialização está associado a dois fenômenos complementares e concomitantes: 0 incremento das desigualdades regionais e a constituição das metrópoles. Tanto um quanto outro fenômeno implicam na formação de grandes correntes de migração interna, através das quais se processa uma maciça redistribuição de população.

A população migrante fugia da miséria e da extrema pobreza em que vivia no campo, frutos de uma estrutura agrária desigual que legava as famílias à submissão e a 
precárias condições de vida. Segundo Eunice Ribeiro Durhan (1978, p. 145), "para o trabalhador rural, a migração se apresenta como uma tentativa de 'melhorar de vida', isto é, de restabelecer, em nível mais alto, o equilíbrio entre as necessidades socialmente definidas e a remuneração do trabalho". Escrevendo posteriormente e em concordância com a autora, João Manuel C. M ello e Fernando Novais (1998, p. 574) ressaltam que "a vida da cidade atrai e fixa porque oferece melhores oportunidades e acena para um futuro de progresso individual, mas também porque é considerada uma forma superior de vida. A vida do campo, ao contrário, repele e expulsa".

É desse modo que migram para as cidades, nos anos 50, cerca de 8 milhões de pessoas, ou $24 \%$ da população rural naquela década, e cerca de 14 milhões de pessoas nos anos 60, ou 36\% da população naquela década (MELO; NOVAIS, 1998). Segundo Rivail Carvalho Rolim (2006, p. 181), "a taxa de crescimento anual das cidades do país na década de 1950 chegou a 6,31\% ao ano, caindo nas décadas de 1960 e seguintes". Essa população se concentrava em grandes centros urbanos como São Paulo e Rio de Janeiro que, na década de 1960, reuniam $24,01 \%$ da população urbanizada. Na cidade de São Paulo a população era de 1326261 habitantes em 1940, subindo com as migrações para 2198096 habitantes em 1950 (DURHAN, 1978, p. 29).

Essa população que migrou para as grandes cidades acabou por se instalar em áreas marginalizadas ou como puderam. De acordo com Eunice Ribeiro Durhan (1978, p. 26), como o migrante recém-chegado se caracterizava pela falta de qualificação e não possuía os documentos necessários, se marginalizava no processo produtivo e se empregava como trabalhador não registrado, não contava com nenhuma proteção legal e dependia do patrão de uma forma mais completa, recriando uma situação em parte muito semelhante a da clientela.

Nesse contexto, havia ainda a situação dos imigrantes e dos negros, que juntamente com os migrantes rurais, formavam a grande maioria da população das grandes cidades. M ello e Novais (1998, p. 582) afirmam que os imigrantes ou filhos destes já estavam em São Paulo havia algumas gerações e obtiveram algum progresso, sendo muitas vezes donos de pequenos negócios ou trabalhavam por conta própria, mas poucos se tornaram grandes empresários. 
De acordo com Boris Fausto (1998), em artigo no qual analisa as características do processo de imigração ocorrido entre 1870 e 1930, a aventura imigratória no Brasil, tomada de seu sentido mais amplo, foi satisfatória, tanto no plano da ascensão social como na integração na sociedade. M as isso não quer dizer que os imigrantes não tenham passado por dificuldades, desde o fracasso na realização de sonhos e a sensação de estranheza por parte do nacional, a qual teve de enfrentar e tentar superar.

Fausto (1998, p. 21) afirma que a São Paulo dos primeiros decênios era conhecida como a "cidade dos italianos". No entanto, esse título "tende a obscurecer o impacto contraditório que produziu a instalação em grande número de imigrantes, desta ou daquela origem, na cidade". Os jornais da época mostram como eles começaram a fazer parte da classe média, num fenômeno de deslocamento social. Por outro lado, censuram sem ressalva os costumes dos habitantes dos cortiços:

Abundam nos jornais as queixas contra as trocas de tiros, obscenidades, algazarras, pelas quais são responsabilizados estrangeiros moradores dos cortiços, quebrando 0 estilo de vida recolhido da cidade cuja propriedade se amplia enormemente (FAUSTO, 1998, p. 22).

No entanto, segundo o autor, esse preconceito contra os imigrantes "expressava, sobretudo, a visão de camadas sociais em declínio ou a aversão de letrados sensíveis à irrupção do pragmatismo e do mau gosto demonstrado pelos novos ricos" (FAUSTO, 1998, p. 24). Os estrangeiros, por sua vez, tinham em comum uma convicção essencial: "todos se consideravam gente devotada ao trabalho, os verdadeiros construtores de uma cidade que ia se convertendo em metrópole" (FAUSTO, 1998, p. 26).

Em relação aos negros, estes viviam em condições difíceis, além de marginalizados. Segundo Mello e Novais (1998, p. 583):

Já a massa de negros das cidades, continuou, após a Abolição, abandonada a própria sorte, ocupada nos trabalhos mais "pesados" e mais precários, muitos vivendo de expedientes, amontoada em habitações imundas, favelas, cortiços, e mergul hada também no analfabetismo, na desnutrição e na doença.

O preconceito de cor no período, mesmo camuflado, era o maior responsável pela situação em que se encontravam os negros na sociedade. Isso se expressava principalmente na distribuição dos empregados, uma vez que havia o predomínio branco nos setores de 
prestação de serviços, indústria, comércio, social, e de construção civil. Somente no setor agrícola é que os números se equiparam.

Este é o cenário do Brasil em meados do século XX. $O$ fato é que a o imigrante estrangeiro, o migrante rural e o negro foram os protagonistas da industrialização acelerada e da urbanização rápida. Mas nem todos foram incluídos no processo de modernização do país, não compartilhando do euforismo da elite com o período, e vivendo em condições difíceis, tendo um padrão de vida que não condizia com esse aparente progresso.

\section{Presunção de periculosidade: determinados segmentos sociais no pensamento jurídico-penal brasileiro}

A realidade social de marginalização de determinados segmentos sociais das grandes cidades permitiu o desenvolvimento de teorias em que as camadas mais pobres eram consideradas mais propensas ao crime, já que suas condições de vida as impeliriam para tal. Um dos aspectos considerados nessas teorias era 0 fato dos migrantes rurais estarem "invadindo" as cidades e ameaçado a ordem nas mesmas. De acordo com Rivail Carvalho Rolim (2006, p. 185):

No Brasil, as teorias referentes à marginalidade social partiram do pressuposto de que as cidades estavam sendo ocupadas por migrantes de regiões atrasadas e arcaicas que, ao encontrarem dificuldades para se integrarem à nova sociedade, viviam em uma situação marginal.

Segundo Rolim (2007, p. 11), os pensadores jurídicos entendiam que esse cenário social era "propicio para o aparecimento de pessoas com comportamentos antijurídicos e anti-sociais. 0 pressuposto era de que esses grupos marginais eram marcados por um alto índice de criminalidade, desorganização familiar e perturbações emocionais".

Nessa conjuntura, desenvolveu-se a idéia, no pensamento jurídico-penal, de que os homens de cor cometiam mais crimes que os brancos por serem social e culturalmente inferiores, estando mal-ajustados a sociedade do período. 0 jurista Nelson Hungria, em artigo escrito na Revista Forense em 1951, analisando quantitativamente os homens presos na década de 1950, revelou que: "o coeficiente de criminalidade dos homens de cor (negros 
e mulatos, isto é, mestiços indo-europeus e negros), é, no Brasil, comparativamente, muito maior que o da população branca" (HUNGRIA, 1951, p. 21).

Procurando as causas disso, Hungria (1951, p. 22) escreveu que vinha sendo atribuído esse fato ao índice de "inferioridade de raça": "os negros e mestiços seriam, organicamente mal ajustados às condições da sociedade civilizada ou ao tipo evoluído da cultura dos brancos. Haveria neles uma acentuada proclividade inata para o crime".

No entanto, segundo Hungria, essa teoria não seria válida para explicar o maior número de crimes cometidos por negros em relação aos brancos. Além disso, a idéia de que a mistura racial seria a responsável por esse fato não é verdadeira, já que a mistura se mostrou positiva em vários países europeus. Da mesma forma, a afirmação da proclividade racial para o crime, bem como a morfologia dos negros e a semelhança com o chimpanzé não explicariam esse fato. E ainda, segundo Hungria, não existia fundamento para a afirmação da degenerescência do mestiço ou mulato, e também para a teoria da transmissão das "características adquiridas" de tribos africanas.

Posto isso, Hungria (1951, p. 26) buscou na sociedade as causas para o cometimento dos crimes pelos negros. Segundo o autor, após a abolição, os negros "foram deixados à sua sorte, inteiramente desprotegidos". Hungria afirma que na sociedade do período os homens de cor viviam em deplorável pauperismo e ineducação. Isto não por serem incapazes de competir com os brancos, "mas do mais profundo descaso a que oram votados depois que terminou para eles o longo martírológio da escravidão".

0 autor afirma que não desigualdades de direitos civis ou políticos em relação aos brancos, já que os homens de cor eram admitidos à vida comum com os brancos: "acontece, porém, que, extinta a escravidão, não foram, de modo geral, devidamente preparados para vencer as desigualdades na sua competição com os brancos" (HUNGRIA, 1951, p. 26).

Sem proteção social e assistência econômica, o negro recém liberto não conseguiu competir com os imigrantes e as vantagens que eles tinham, e foram "engrossar a cauda dos desajustados, dos 'chomeurs', dos vagabundos das estradas ou da multidão de mendigos e desocupados das cidades" (Hungria, 1951, p. 26). Assim sendo, "o fenômeno da maior criminalidade de cor decorre, preponderantemente, de fatores exógenos" (HUNGRIA, 1951, p. 27). 
Vemos delinear, desse modo, uma nova concepção sobre criminalidade, neste caso, dos negros, refutando as teorias biológicas e antropológicas ainda em vigor naquele período, passando a dar ênfase aos fatores sociais como principais responsáveis pela delinqüência de determinados setores da sociedade.

Nessa mesma direção, em artigo escrito na Revista da Faculdade de Direito de São Paulo em 1958, Luiz Fernandes Lima analisa a periculosidade das multidões dos grandes centros urbanos em meados do século XX. Lima (1958, p. 13) escreve que as multidões delinqüentes mereciam atenção especial porque as condições do meio ambiente social (do período) propiciavam a formação de grupos multitudinários dispostos a "tudo, a matar, a depredar, bem como aclamar e aplaudir". Isso se daria porque reinaria a idéia que a multidão pode obter aquilo que nem sempre é desejado individualmente, a reivindicação de classe. Para o autor, "em virtude das condições do meio ambiente social, com facilidade surge, num relâmpago, o grupo multitudinário, disposto a tudo, a matar, a depredar bem como a aclamar e aplaudir". (LIM A, 1958, p. 13).

Lima escreve que com a formação das classes trabalhadoras, a tomada de consciência do trabalhador, do "eu de classe", favorece a composição imediata de multidões e indivíduo, mesmo sozinho, passa a pensar e agir em grupo. 0 progresso facilita a diversificação das multidões classistas distintas, já que há uma grande facilidade de se reunirem em multidão (a qual traz o germe do crime em seu seio). Segundo o autor, "nem toda multidão delinqüe, as toda multidão é condição para a prática dos crimes"

De acordo com o autor, o homem imita um ao outro desde criança, e essa imitação destrói a originalidade e uniformiza as diferenças. "Esse instinto imitativo, que tão fortemente atua sobre os indivíduos isolados, cresce de poder na medida do número de pessoas". A imitação se transmite, para alguns, por contágio moral, como se fosse uma doença. E o meio de locomoção da doença imitativa é a sugestão, que é um fenômeno físicoorgânico, que recebe estímulos externos. Nas pessoas reunidas em multidões, a sugestão atua mais rápida e poderosamente. 0 número tem grande importância, assim como o fator intelectual: "o indivíduo inculto é mais sugestionável que o culto".

Assim, no pensamento jurídico penal de meados do século XX havia uma percepção de que determinados segmentos sociais nos centros urbanos eram pessoas que mereciam receio por parte do poder judiciário e também por parte do restante da sociedade. Devido as 
suas "condutas", "condições de vida", ou mesmo às "práticas sociais e culturais", não respeitavam as normas e estariam mais propensos a comer crimes. Segundo Rolim (2007, p. 13):

Se por um lado o positivismo penal do início do século XX dava grande ênfase à existência de sinais físicos para definir o criminoso, por outro abria espaço também para se considerar o ambiente social como responsável pela geração de pessoas criminosas, porque havia 0 entendimento de que 0 meio provocava 0 enfraquecimento dos hábitos, a perturbação dos vícios e das taras.

\section{Alguns aspectos históricos da presunção de periculosidade}

Em artigo escrito na Revista de Direito da Universidade de São Paulo em 1954, A. Almeida Junior, catedrático de Medicina Legal, recupera alguns aspectos históricos da presunção de periculosidade no direito penal. Em primeiro lugar, ressalta que o Código Penal de 1940 acolheu em seu texto as noções de "periculosidade" e de "defesa social", dando aos juízes a tarefa de verificar se certos indivíduos são ou não perigosos. A. Almeida Junior (1954, p. 221) esclarece a definição de "perigoso" presente no Código:

'Perigoso' é todo aquele que virá provavelmente a delinqüir (se ainda não o fez), ou provavelmente reincidirá (se já inaugurado no crime). Periculosidade pré-delitiva ou 'social' no primeiro caso (arts. 14 e 27 do Código); periculosidade post-delitiva ou 'criminal' no segundo.

A. Almeida Junior (1954, p. 222) afirma que as bases para fixar a periculosidade de um indivíduo eram as mesmas para antecipar a conduta dos homens em geral: "0 conhecimento da personalidade de cada um e a natureza dos estímulos que incidem sobre eles". 0 autor afirma ainda que "sem essa possibilidade seria inteiramente inconcebível a vida social, cujo funcionamento depende do grau de confiança que temos na relativa coerência das reações dos que dela participam".

Segundo Almeida Junior (1954, p. 223), no caso de verificação da periculosidade, a lei não pede a "convicção" que seria indispensável para condenar, bastando uma "suposição" (art. 77), "e quem fala em suposições se coloca desde logo no domínio das afirmações probalísticas".

Posto isto, o autor inicia uma exposição sobre os fatos e circunstâncias utilizados no passado para "autorizar a suposição" de que determinado indivíduo era ou não perigoso. A 
ciência Fisionômica, empregada a partir do século XIV, utilizava como critérios de presunção de periculosidade a fisionomia dos indivíduos, comparando-as com os animais. "A má catadura ("mala phisonomia") era para eles sinal de celeradez, e, em caso de suspeita, constituía elemento suficiente para a tortura" (ALM EIDA JUNIOR, 1954, p. 226). Mas a falta de precisão dos diagnósticos fez com que fosse desacreditada.

A Frenologia, apesar de seu aspecto científico, teve pouca duração. Franz J. Gall elaborou seus princípios, que podem ser descritos como: “ $1^{\circ}$ ) cada faculdade mental tem por sede determinada região do córtice cerebral; $2^{\circ}$ ) 0 desenvolvimento das diferentes zonas corticais é proporcional ao das faculdades respectivas; $3^{\circ}$ ) esse desenvolvimento se denuncia através de correspondentes saliências no crânio" (ALM EIDA JUNIOR, 1954, p. 227). Se os fisionomistas olhavam a face, os frenologistas apalpavam a cabeça dos indivíduos. E seria dado o diagnóstico de perigoso nos seguintes casos: "se há saliências logo acima ou logo atrás das orelhas, indicado exagero da 'destrutividade' ou da 'combatividade, em contraste da pequenez da 'benevolência', no pólo, tem-se um assassino" (ALM EIDA JUNIOR, 1954, p. 227). Novamente, a falta de precisão dos diagnósticos desacreditaram tal teoria.

Nas últimas décadas do século XIX, constituiu-se a Antropologia Criminal, baseada nos métodos e doutrinas criminológicas de Cesar Lombroso. Para Almeida Junior, seu programa era abranger o estudo individual do criminoso, interessando bastante à solução do problema da periculosidade. Segundo Lombroso:

Existiria entre os homens um 'tipo criminal', reconhecível pela presença de caracteres físicos tais como "cabelo geralmente escuro e crespo, submicrocefalia, assimetria macrânica e facial, olhos oblíquos, implantação anormal das orelhas, escassez de barba, nistagmo, midríase, desigualdade entre as pupilas, nariz torto, fronte fugidia, face alongada, zigomas e mandíbula muito desenvolvidos, ampla abertura dos braços, semelhante entre os dois sexos" (ALM EIDA JUNIOR, 1954, p. 227).

Além da verificação empírica, Lombroso atribuiu uma patogênese aos sinais verificados nos homens "perigosos": a degenerescência. "Em virtude de causas diversas, que atuariam por via hereditária (entre as quais em primeiro lugar a epilepsia, e, depois, 0 alcoolismo, a sífilis e outras), seriam lesados os centros nervosos e, por intermédio deles, todo o organismo" (ALM EIDA JUNIOR, 1954, p. 229). E mais: 
A degener escência consistiria na parada do desenvolvimento do indivíduo, em fase correspondente a um estágio intermediário de sua evolução. Assim os estigmas encontrados no corpo ou no espírito do criminoso, seriam marcas 'atávicas', lembrando a infância, a vida fetal ou mesmo a ancestralidade da espécie humana (ALMEIDA JUNIOR, 1954, p. 229).

No entanto, as idéias de Lombroso foram paulatinamente abandonadas a partir das pesquisas desenvolvidas por Morel sobre a hereditariedade, as quais fizeram ruir as "vigas mestras da Antropologia Criminal lombrosiana". Segundo Almeida Junior (1954, p. 230), os dois fatos afirmados por Lombroso, "o da vultosa proporção de criminosos 'natos' e o da presença, neles, de estigmas corporais denunciadores", deveriam ser abandonados e negados:

A influência da hereditariedade na produção de criminosos é fraca e inespecífica, não se aceitando que exista herança direta de tendência para o crime. $E$, quanto aos estigmas corporais reveladores, que permitiriam 0 diagnóstico da periculosidade, 0 acordo é hoje quase unânime no sentido de recusá-los.

A Antropologia criminal, apesar de pretender o estudo da personalidade do indivíduo como um todo, centrou suas atenções nos fatores morfológicos e constitucionais, não dando, para Almeida Junior, a devida atenção ao fator psicológico. Nessa perspectiva, o importante era encontrar os fatores, através do exame morfológico, que, "atuando sobre 0 psiquismo do indivíduo, determinaram o seu desvio de conduta" (ALM EIDA JUNIOR, 1954, p. 238).

Os estudos das secreções internas a partir da segunda metade do século XIX fixaram, segundo Almeida Junior (1954, 232), bases para a explicação das correlações sômato-psíquicas: "glândulas como a tireóide, as supra-renais, a hipófise, as células intersticiais testiculares e os f olículos ováricos, elaboram certos produtos, - os hormônios, e os lançam diretamente no sangue". A partir dessa perspectiva de verificação da periculosidade, cada organismo possui uma "constelação endócrina" própria, a qual influência a personalidade psíquica e a estrutura do corpo. É nesse sentido que nasce a concepção de "biótipos" humanos, que seriam "tipos reconhecíveis por determinado conjunto de caracteres morfológicos e funcionais. e que servem de 'centros de referência' para a comparação dos indivíduos que se estudem". 
Nesse sentido, surge a Biotipologia Criminal, "a ciência que estuda o delinquente sob a tríplice feição morfológica, dinâmico-humoral e psicológica, com o fim de fixar-Ihes as características individuas para prover às necessidades da Policia e da Justiça" (ALM EIDA JUNIOR, 1954, p. 233). Assim, os biotipologistas procuraram predizer qual a espécie de delinqüência de 0 individuo era capaz de cometer a partir de seu biótipo. Mas a biotipologia encontrou críticas porque, além de saber se o individuo era um possível delinqüente, também pretendia saber qual o delito que o mesmo cometeria.

Já os criminologistas norte-americanos, nas primeiras décadas do século XX, ofereceram as bases para o estudo dos fatores sociais ou da personalidade, determinando, a partir de dados estatísticos, inúmeros fatores que levariam o indivíduo a delinqüir, e dando grande importância ao regime de trabalho, indicando que as pessoas que não trabalhavam estavam mais propensas a cometer os delitos.

No Brasil de meados do século XX, apesar de algumas proposições ainda estarem em vigor, surge no pensamento jurídico-penal uma nova concepção sobre os indivíduos que fundamentaria a presunção de periculosidade nos mesmos, qual seja, a de que os fatores presentes na sociedade é que seriam os grandes responsáveis pela delinqüência cometida por alguns setores da sociedade. Para Rolim (2006, p. 290):

Os operadores jurídicos, pelo fato de terem que aturar sobre a sociedade, fazendo, inclusive, uma prévia valoração das condutas, não ficaram indiferentes às reflexões que apontavam novas perspectivas para a compreensão das relações sociais do país. Com isso, estabeleceram um diálogo com o pensamento social em curso para que pudessem produzir uma análise consistente acerca da conduta e do comportamento das classes populares.

É certo que, os setores visados por essa concepção eram os grupos sociais que se encontravam na liminariedade da sociedade, ou seja, aqueles com condições econômicas menos favoráveis. Este é, provavelmente, o germe de uma postura judiciária adota muito frequentemente a partir da segunda metade do século XX, a de criminalizar a pobreza, dando aos pobres um tratamento desigual, ao presumir sua periculosidade.

\section{Considerações finais}


Tendo em vista que o pensamento jurídico não está dissociado da dinâmica, nossas reflexões centrarem-se na conjuntura histórica delimitada entre os anos de 1945 e 1964, período no qual a sociedade brasileira passou por processo de modernização e industrialização sem precedentes, cujas transformações decorrentes deram nova configuração as cidades como São Paulo, por exemplo. Esse processo implicou em transferências maciças de população das zonas rurais para as urbanas, formando grandes correntes migratórias.

No entanto, essa população migrante acabou por se instalar em áreas marginalizadas ou como puderam, indo juntar-se a população de imigrantes e negros já residentes nas cidades. Essa realidade social permitiu que os pensadores jurídicos do período desenvolvessem a idéia de que determinados segmentos sociais encontravam-se mal ajustadas na sociedade e que, portanto, estariam mais propensas ao crime.

A presunção de periculosidade que recaiu sobre esses setores sociais estava relacionada, desse modo, com as condições sociais em que se encontravam os indivíduos, refutando, assim, as teorias antropológicas e biológicas ainda em vigor naquele período. Cria-se, então, um novo conceito de culpabilização desses segmentos sociais, direcionando as atenções para os padrões sócio-culturais presentes na sociedade do período.

\section{Referências}

ARRUDA, M aria Armandina do Nascimento. Metrópole e Cultura: São Paulo no meio século XX. São Paulo: EDUSC, 2001.

BOURDIEU, Pierre. A força do direito: elementos para uma sociologia do campo jurídico. In: O PODER Simbólico. Trad. Fernando Tomaz. São Paulo: Diefel, 1989.

DURHAN, Eunice Ribeiro. A caminho da cidade. São Paulo: Perspectiva, 1978.

FAUSTO, Boris. Imigração: cortes e continuidades. In: SCHW ARCZ, Lilia M oritz (Org.). História da vida privada no Brasil: contrastes da intimidade contemporânea. São Paulo: Cia das Letras, 1998. v. 4.

JUNIOR, A. Almeida. A verificação da periculosidade. Revista de Direito da Faculdade de São Paulo, São Paulo, v. 49, 1954.

HESPANHA, M anuel. A História do Direito na História Social. Lisboa: Livros Horizonte, 1978. 
HUNGRIA, Nelson. A criminalidade dos homens de cor no Brasil. Revista Forense, v. 134, mar. 1951.

LIM A, Luiz Fernandes. Os crimes das multidões. Revista da Faculdade de Direito de São Paulo. São Paulo, v. 53, 1958.

NEDER, Gizlene. Discurso jurídico e ordem burguesa no Brasil. Porto Alegre: Sérgio Antonio Fabris, 1995.

MELLO, João Manuel C.; NOVAIS, Fernando A. Capitalismo tardio e sociabilidade moderna. In: SCHWARCZ, Lilia Moritz (Org.). Historia da vida privada no Brasil: contrastes da intimidade. São Paulo: Cia das Letras, 1998. V 04.

ROLIM, Rivail Carvalho. Culpabilização da pobreza no pensamento jurídico-penal brasileiro em meados do século XX. IN: KOERNER, Andrei (Org.). História da justiça penal no Brasil: pesquisas e análises. São Paulo: IBCCRIM, 2006.

. Direito, justiça e cidadania na perspectiva da história social do direito. Revista Espaço Acadêmico, n. 50, jul. 2005.

. Pensamento jurídico sobre a criminalidade negra no Brasil, 1940-1960. Revista The Latin Americanist. Charlote, Carolina do Norte - EUA, v 51, n. 1, 2007.

RUSCHE, Georg; KIRCHHEIM ER, Otto. Punição e estrutura social. Rio de Janeiro: Revan, 2004. VON SAVIGNY, Friedrich Carl. O sistema do direito romano atual. Ijuí: Editora Inijuí, 2004. 